\title{
Note from the Editors
}

The present volume of the NWR marks a major change in the way the journal is published: we have shifted to continuous submission and publication model. This model is, we think, better suited for Open Access electronic publication than our previous one with two issues per volume and year, which was designed for traditional print media. We can already see several advantages with our new publication format: Continuous publication makes research available for the community as quickly as possible, since we do not have to wait for a deadline to publish individual contributions. This is beneficial for both readers and authors. The continuous publication model also facilitates the open review process, shortens turnaround time and increases the visibility of individual contributions.

On this model submissions are, as soon as they have gone through the review process and been accepted for publication, released online for open review. Issues build gradually, with articles being added to the contents list as soon as they have undergone a first copyedit. The "issue in progress" is the issue that is open and to which we are continuously adding new articles. At the end of the year, the issue is closed and published as an annual volume, which will in addition be available as print on demand.

This also means that we no longer have specific deadlines for submissions. Instead, received submissions are processed continuously, and submissions that are accepted after peer review are released online with as little delay as possible. In fact, it would have been very difficult to produce two ordinary issues under the rather extraordinary circumstances we have experienced during the year. The new publication model, however, gave us the flexibility needed to finish a volume that contains roughly as many pages and articles as previous, traditional volumes.

It is also encouraging that the number of submissions has not been significantly affected by the pandemic. This also means that we 
have to maintain a high level of selectivity regarding publication. We are, however, very grateful for all submissions and want to thank all the authors who thought of NWR as a venue for their publications. The high number of submissions resulted in a high demand of peer reviewers during the year, and we want to thank them all for their valuable work in maintaining the quality of the journal.

We are also pleased that our print on demand solution for ordering back issues is finally fully functional. Click on "Print on Demand" on the journal's homepage and you will be directed to our webshop. The present issue will hopefully be added to the catalog at the beginning of next year.

As always, you are welcome to contact the Editor-in-Chief with any comments or queries you might have.

$$
\text { Bergen-Uppsala-Norwich-Stavanger }
$$

December 2020

The editors

Simo Säätelä, Gisela Bengtsson, Oskari Kuusela \& Cato Wittusen 